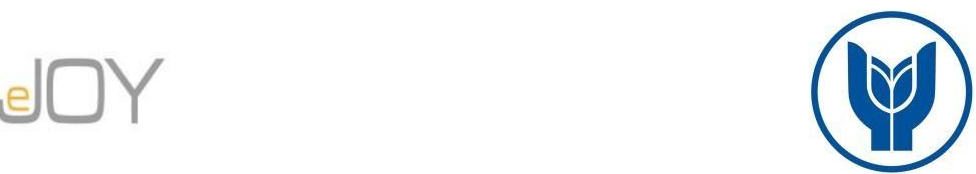

Antmen, Z., F., Erik, A. / Journal of Yasar University, 2019, 14/55, 266-276

\title{
Kısıtlar Teorisi Kavramının Başa baş Analizi ile Birlikte Değerlendirilmesi ve Uygulaması
}

\section{Evaluation of the Theory of Constraints Concept with the Break Even Point Analysis and its Application}

\author{
Zahide Figen ANTMEN, Çukurova Üniversitesi, Türkiye, zfantmen@ hotmail.com \\ Adem ERIKK, Türkiye, admerk01@gmail.com
}

\begin{abstract}
Öz: Bir işletmenin performansını etkileyen kısıtların var olduğunu ve işletmenin etkin yönetilememesinin bu kısıtlarla ilişkili olduğunu savunan yönetim sistemine Kısıtlar Teorisi denir. Issletmenin performansının iyileștirilebilmesi ancak bu kısıtların tespit edilip ortadan kaldırılması ile mümkün olabilir. İşletmelerin sürekliliğinden dolayı ortaya çıkacak kısıtların da sürekli bir iyileştirme ve geliştirme sürecinde takip edilmeleri gerekmektedir. Işsletmeler kar planlaması yaparken oluşabilecek kısıtların var olduğu gerçeğini göz önüne almalıdırlar.

Bu çalışma kapsamında kısıtlar teorisinin varsayımları altında başa baş analizine yeni bir bakış açısı getirilmeye çalışılarak var olan klasik başa baş analizi ile karşılaştırılmalar yapılmıştır. Kısıtlar teorisinin beş adımlık algoritması sayesinde işletmede var olan kısıtlardan en önemlileri seçilmiş ve bunlar iyileştirilmiştir. Yapılan çalışma sonunda işletmenin var olan karlılığ l yaklaşık olarak otuz yedi katına çıkarılmıştır. Ayrıca işletmenin maliyet analizi yapılarak kapasitelerini ne kadar verimle kullandıkları ortaya konulmuştur. Bütün bu analizler ve iyileştirmeler yapılırken kurulan optimizasyon modelinden ve GAMSside programından yararlanılmıştır.
\end{abstract}

Anahtar Kelimeler: Kısıt, Kısıtlar Teorisi, Başa baş Analizi, Optimizasyon Modelleme

\begin{abstract}
The management system which argues that there are constraints affecting the performance of an enterprise and that the inability to manage the enterprise effectively is related to these constraints, is called the Theory of Constraints. Improving enterprise's performance can only be achieved by identifying and eliminating these constraints. The constraints should be followed in a continuous improvement and development process due to enterprise's continuity. Enterprieses should take into consideration the fact that constraints that may occur when profit planning.

Within the scope of this study, we tried to bring a new perspective to the break even point (bep) analysis under the assumptions of the theory of constraints and compared with the existing classical break even point analysis. Thanks to the 5-step algorithm of the constraints theory, the most important constraints in the enterprise were selected and improved. At the end of the study, the profitability of the company was increased to nearly 37 times. In addition, it was revealed that they use their capacity with how much efficiency by doing the cost analysis of the enterprise. The optimization model and optimization package program were used while all these analyzes and improvements were doing.
\end{abstract}

Keywords: Constraint, Theory Of Constraints, Break Even Point Analysis, Optimization Modelling

\section{Giriş}

İşletmelerin yaşamlarını sürdürebilmelerinin temel hedefi kar elde etmektir. Hedefe ulaşma sürecinde pek çok engelle karşılaşılır. Karşılaşılan engeller aynı zamanda işletmelerin sürdürülebilir büyümelerini de engelleyen etkenler olarak ortaya çıkabilir. Bahsi geçen engellerin hepsine birden kısıt denir. İşletmede ortaya çıkan maliyetler işletme karını en çok etkileyen kısıtlardır. İşletme yönetiminin kararlarını ve amaçlarını etkileyen bu kısıtlar ancak iyi yönetilirse işletme amacına ulaşmış olacaktır (Kaygusuz, 2011). Kısıtlar Teorisi bu etkenleri en iyi şekilde yönetmeyi hedefleyen ve bunu yaparken de bu kısıtları ortadan kaldırmayı savunan bir teoridir. Sistemde bütün süreçler birbirini etkileyen bir zincir mantığında çalışır, işletmenin verimliliği en zayıf halkaya yani aksaklık yaşanan sürece bağlıdır (İlhan, 2014).

Kısıtlar Teorisi, süreçlerin performansını etkileyen en az bir kısıtın olduğunu ve bunların yönetilerek ortadan kaldırılmasını savunan bir yöntemdir (Ayanoğlu, Şakar, 2015). Aynı zamanda Kısıtlar teorisi finansal ve operasyonel kısıtlar da içermektedir. Net kar, yatırım vb. finansal kısıtları oluştururken, katkı, envanter ve faaliyet giderleri de operasyonel kısıtları oluşturur. (Akman, Karakoç, 2005). Kısıtlar Teorisi sürekli iyileşmeyi sağlayan beş adımlık bir algoritmadan oluşmaktadır (Şahbaz 2005).

Algoritmanın ilk adımında her kaynağın kapasitesi ve kapasite üzerindeki yükler hesaplanır daha sonra pazar talebi ile karşılaştırılır. Eğer Pazar talebi büyükse kaynak kısıttır. İkinci adımda, kısıtın kullanıldığı tüm ürünlerde karlılığa bakılarak hangi ürünlerin kaynağı daha çok kullanması gerektiğine karar verilir. Karar aşamasından sonra belirlenen kaynaktan hangi ürünlerin ne kadar üretileceği bellidir ve kar sıralaması büyükten küçüğe doğru yapılarak darboğaz kapasitesi dolana dek ürün yüklemesi yapılır. Böylece ürün karması belirlenmiş olur (Net Kar = Çıktı - İşletme Giderleri). Üretim sürecinde var olan kısıt veya kısıtlar, hangi üründen ne kadar üretilmesi gerektiğini ve sonuçta işletmenin ne kadar para kazanacağı bilgilerini vermiş olur. Üçüncü adımda sistemde kısıt olmayan hiçbir kaynağın gereğinden fazla kullanılmaması ve kaynakların çalışması için hammadde ve malzeme verilmemesi gerektiği ile ilgilidir. Dördüncü adımda 
ise sistemdeki kısıt veya kısıtlar birtakım yöntemler kullanılarak ortadan kaldırılır ve son olarak eğer önceki adımlarda bir kısıt kaldırılmışsa adım bir'e geri dönülmeli ve ataletin kısıt haline gelmesine izin verilmemelidir. Eğer sistemdeki kısıt varlığını sürdürüyorsa adım ikiye dönülerek gerekli çalışmalar yeniden yapılmalıdır.

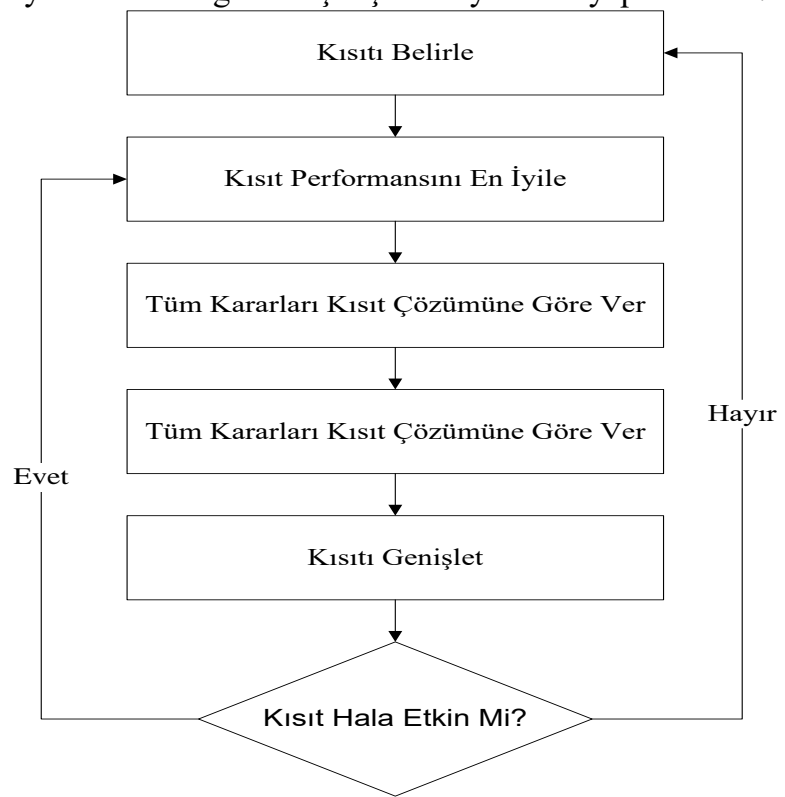

Şekil 1. Kısıtlar Teorisinin Beş Adımı (Gaga,2009)

Kısıtlar teorisi kısıt denilen çeşitli kaynak sınırlarından oluşur. Bu kısıtlar paradigma (davranış), politika (yönetim) ve fiziksel (malzeme, kapasite, lojistik, pazar vb.) kısıtlar olmak üzere üç ana başlık altında toplanmıştır (Özdemir, 2007). Kısıtlar teorisinin çalışma alanları sınırsız denilebilecek ölçüdedir. Başlıca kullanım alanları üretim, dağıtım ve kaynak zinciri, pazarlama, strateji planlama ve proje planlamadır (Atay, 2009). Her bir alanda çeşitli işlevlere sahip olan kısıtlar teorisi üretimi sistem olarak ele alır ve sistemin verimliliğini sağlamaya, dağıtım ve kaynak zincirinde stok maliyeti ve elde bulundurmama maliyetlerini iyi yöneterek doğru yerde ve zamanda teslimatı gerçekleştirmeye, pazarlamada istenilen kâr marjı ve satışı sağlamak için pazarda reddedilmeyecek ürün ve hizmeti sağlamaya çalışır (Atay, 2009).

Kısıtlar teorisinde, sistemin ana problemleri üzerinde yoğunlaşmak için çeşitli araçlar kullanılmakta ve bu araçlara genel olarak düşünme süreçleri denilmektedir (Çolak, 2013). Bu süreçler; neyin değişeceğine karar verme, neyle değiştirileceğine karar verme ve değişikliğin nasıl yapılacağına karar vermektir (Goldratt, 1990). Bu süreçler gerçekleştirilirken neden-sonuç ilişkisi çerçevesinde değerlendirilir.

Kısıtlar teorisinde kullanılan araçlarından biri de Tambur-Tampon-İp (TTİ) yöntemidir. Bu yönteme göre "Tambur”, sistemdeki akış hızını aksatan kısıtlayıcı etmen, "Tampon” koruyucu zaman, "İp" ise üretimin kısıtlayıcı etmenin hızında devam edebilmesi için işi (veya malzemeyi) tezgâha çeken zamanlama programıdır (Basık, 2012). Kısıtlar teorisinde maliyet hacim ilişkileri klasik anlayıştan farklı olarak üretim miktarına değil satış hacmine bağlı olarak değişmekte ve direkt ilk madde ve malzeme gideri ile beraber enerji giderleri ve dağıtım giderleri değişken kabul edilerek geri kalan maliyetler sabit alınmaktadır. Kısıtlar Teorisi, sistemin hasılatının, maliyetinin, karının ve nakit akışının, sistemin kısıtı veya kısıtları tarafından belirlendiğini savunmaktadır (Kaygusuz, 2011).

Çalışmanın ilk bölümde kısıtlar teorisi hakkında bilgi verilerek kısıtlar teorisi ile ilgili bir kısım çalışmalar ayrıntılı olarak irdelenmiştir Daha sonraki bölümde Kısıtlar Teorisinin başa baş analizi ve karlılık ile ilgili en iyi ürün karması hedeflenerek matematiksel bir model kurulmuştur. Dördüncü bölümde kurulan matematiksel modelin uygulaması gerçekleştirilmiş ve son bölümde ortaya çıkan sonuçlar ve öneriler değerlendirilmiştir.

\section{Literatür Taraması}

Akman ve Karakoç (2005), çalışmalarında, performans iyileştirmek için yazılım geliştirme prosesinde Kısıtlar Teorisi yöntemlerinin nasıl kullanılabileceğini amaçlamışlardır. Herhangi bir yazılım geliştirme prosesinde var olan darboğazların tespit edilerek giderilmesi ve prosesin performansının artırılması konusunda kısıtlar teorisinin düşünce süreçlerinin, yani sorun çözme araçlarının kullanımına ilişkin örnek bir uygulama gerçekleştirmişlerdir.

Golmohammadi (2015), daha önceki çalışmaların büyük bir kısmının kısıtlar teorisi kavramı ve basit süreç uygulamaları üzerine olduğu belirtilmiştir. Çalışmasında kısıtlar teorisinin işyerleri sistemlerine yönelik kuralları üzerine yoğunlaşmış ve bu kuralların uygulamadaki adımlarına ve zorluklarına dikkat çekmiştir. Kısıtlar teorisine dayanan zamanlama kuralları otomotiv endüstrisinde bir vakaya uygulanmıştır. Bir (simülasyon) benzetim modeli ile ana üretim çizelgesi, tambur-tampon-ip ve benzeri konular hakkında bilgiler verilmiştir.

Küçüksavaş, Tanış ve Ünal (2005), çalışmaları ile firmaların karlılıklarının arttırılabilmesi için, üretim sürecinde ortaya çıkan kısıtların tespit edilip ortadan kaldırılmasının yani kısıtların yönetilmesinin önemine yönelik bir araştırma 
yapmayı amaçlamışlardır. Bu bağlamda, öncelikle Kısıtlar Teorisini teorik olarak incelemişler, daha sonra bir imalat firmasında yapılan tanımlayıcı ve keşifsel olay çalışmaları ile teorinin firma karına olan etkisini ortaya koymuşlardır.

Kaygusuz (2006), üretime devam veya üretime son verme kararlarının özel bir türü olan üretim veya satın alma alternatifleri arasında Kısıtlar Teorisi anlayışına göre nasıl bir değerlendirme yapılacağı çalışmasının temel konusunu oluşturmaktadır. Klasik maliyet analizleri ve Kısıtlar Teorisi anlayışına göre en uygun üretim veya satın alma kararının nasıl verileceğini karşılaştırmalı olarak incelemiştir. Çalışmada Kısıtlar Teorisi ve MS Office Excel programını birlikte kullanarak verilecek üretim veya satın alma kararının geçerliliği test edilmiştir. Kısıtlar Teorisi anlayışının savunduğu temel anlayış, işletmenin karı, satışlara bağlı olarak artmakta veya azalmaktadır. Kaygusuz çalışmasında yaptığı uygulama sonucunda bu anlayışın geçerliliğini test etmiştir.

Boyd ve Gupta (2004), yaptıkları çalışmalarında operasyon yönetimini ele alarak bu konuda çalışan araştırmacıların kapsayıcı bir model ortaya koyamadıklarını belirtmiştir. Bu araştırmacıların çok azı kısıtlar yönetimi ile ilgilenmiştir. Ancak operasyon yönetimi ile ilgilenen bazı araştırmacılar kısıtlar yönetiminin operasyon yönetimini büyük çoğunlukla kapsayacak bir teori olabileceğine inanmamaktadırlar. Bu çalışmada işletme yönetiminde kısıtlar yönetimi kurulumu için hipotezler önerilmiştir.

Küçüksavaş, Ünal ve Demircioğlu (2006), çalışmalarında firmaların rekabet ortamında pazar paylarını ve karlılıklarını artırabilmek için ürün karması kararlarının önemini vurgulamışlar, doğru ürün karması kararları alabilmede Kısıtlar Teorisi ve faaliyete dayalı maliyet sistemi entegrasyonunun önemini ortaya koymayı amaçlamışlardır. Bu çerçevede, öncelikle, faaliyete dayalı maliyet sistemi, ardından Kısıtlar Teorisi incelenerek, daha sonra her iki yöntemin entegrasyonunu ortaya koymuşlardır. Çalışmanın sonunda faaliyete dayalı maliyetlendirme ve Kısıtlar Teorisinin entegre edilmesi suretiyle belirlenen ürün karması ile ayrı ayrı faaliyete dayalı maliyetlendirme ve Kısıtlar Teorisine göre daha yüksek karlılık sağladığı bulunmuştur.

Izmailov ve arkadaşları (2016), çalışmalarında proje yönetimi için kullanılan bir kısıtlar teorisi aracı olan Kritik Zincir Proje Yönetimi kavramını ele almışlardır. Aynı anda tek veya çok projeli yapılarda kaynak kullanımını yönetmede kullanılan bu yöntem zararlı olan mevcut standartları ortadan kaldırmakta, kaynaklar ve görevler arasındaki ilişkiyi ve zamanında yapılmasını dikkate almaktadır. Çalışmada kritik zinciri ve arabellekleri dikkate alarak ve birden fazla proje senkronizesini sağlamak için araç olan tampon yönetimini kullanmışlardır.

Atmaca ve Terzi (2007), çalışmalarında öncelikli olarak Tam Zamanında Üretim felsefesini incelemiş ve stratejik maliyet yönetimi açısından maliyetleme yapmışlardır. Daha sonra kısıtlar teorisi incelenerek stratejik maliyet yönetimi açısından maliyetlemeyi yapmışlardır. Tam Zamanında Üretim ve Kısıtlar Teorisi yaklaşımlarını karşılaştırmışlardır.

Utku ve Ersoy (2008), çalışmalarında Kısıtlar Teorisine ait yeni bir muhasebe yaklaşımı olan süreç katkı muhasebesini açıklamışlar, Kısıtlar Teorisi ve süreç katkı muhasebesinin, geleneksel maliyet muhasebesi yöntemleri (tam-değişken) ile çağdaş maliyet muhasebesi yöntemlerinden faaliyet tabanlı maliyetlendirme yöntemi ve stratejik maliyet yöntemi ile karşılaştırarak arada ki benzerlik ve farklılıkları ortaya koymuşlardır. Gerı ve Nıv (2008), çalışmalarında büyük endüstri, ticaret ve hizmet işletmelerinde Kısıtlar Teorisi aracılığıyla örgütler arası sistem oluşturma sürecini incelemişlerdir.

Büyükyılmaz ve Gürkan (2009), çalışmalarında kısıtlar teorisinin teorik yapısını ortaya koymaya çalışarak konuya ilişkin temel kavramları incelemişleridir. Ayrıca diğer yönetim yaklaşımları ile karşılaştırmaya gitmeden teorinin işletmelere sağladığı yenilikleri ve faydaları ortaya konulmaya çalışılmışlardır. Bu amaç doğrultusunda kısıtlar teorisine ilişkin literatürde yer alan çalışmaları incelemişler ve sonuç olarak teorinin, amaçlara ulaşmayı engelleyen sorunların belirlenmesi ve ortadan kaldırılmasında klasik yaklaşımlara göre daha etkili çözümler sunduğunu belirlemişlerdir.

Küçüksavaş, Demircioğlu ve Demircioğlu (2010), çalışmalarında Kısıtlar Teorisinin; tam ve değişken maliyet sistemi, faaliyete dayalı maliyet sistemi, tam zamanında üretim sistemi ve toplam kalite yönetimi arasındaki ilişkiyi ortaya koymayı amaçlamışlardır. Bu çerçevede öncelikle Kısıtlar Teorisini incelemişler, daha sonra diğer yöntemlerle ilişkisini açıklamışlardır.

Kaygusuz (2011), çalışmasında kısıtların işletmenin performansını nasıl etkilediğini incelemiştir. Kısıtların işletmenin performansı üzerindeki etkilerini göstergeler yardımıyla açıklamaya çalışmıştır. Özellikle maliyet hacim kar analizine odaklanmıştır. Excel çalışma sayfasından geliştirilen bir doğrusal programlama modeli ile kısıt ortamında maliyet hacim kar analizleri ve ilgili göstergeleri incelemiştir. Modelin çözümünde MS Office Excel çözücü aracını kullanmıştır.

Yüksel (2011), çalışmasında bir üretim işletmesinde üretim sürecinin etkinliğini etkileyen faktörlerin belirlenmesinde ve bu faktörler arasındaki ilişkilerin açıklanmasında Kısıtlar Teorisinin düşünce süreçlerinden yararlanılmasını açıklamıştır. Çalışmasında Kısıtlar Teorisi düşünce süreçlerinin, bir üretim sürecinin iyileştirilmesindeki uygulamasını göstermeyi amaçlamıştır. Mevcut gerçeklik ağacından yararlanılarak üretim sürecinde istenmeyen etkilere neden olan kök problemi tanımlamış ve kök problemin ortadan kaldırılması için buharlaşan bulut aracından nasıl yararlanılabileceğini değerlendirmiştir.

Aytekin, Yörükoğlu ve Akman (2012), çalışmalarında kısıtlar teorisinin düşünce süreçlerinin kullanımına ilişkin örnek bir uygulama gerçekleştirmişlerdir.

Ayanoğlu ve Şakar (2015), çalışmalarında kargo firmalarının yoğun dönemlerde ortaya çıkan ek talepleri optimizasyonu bozmayacak şekilde karşılayabilmeleri için alternatif planlar geliştirmeyi amaçlamışlardır. Sonuç olarak çalışmalarında yoğun dönemlerde ek taleplere cevap vermekte zorluk yaşayan firmalara aydınlatıcı bir bakış açısı sunmuşlardır. 
Demircioğlu ve Demircioğlu (2016), çalışmalarında işletme karlılığının artırılmasında önemli olan üretme-satın alma kararında, faaliyete dayalı maliyet sistemi ve Kısıtlar Teorisini kullanarak ve elde edilen karlılık sonucunu geleneksel yöntemle belirlenen karlılık sonucu ile karşılaştırmayı amaçlamışlardır. Bu çerçevede, örnek bir işletmede üretme-satın alma kararları için doğrusal programlama modeli kullanarak faaliyete dayalı maliyet sistemi ve Kısıtlar Teorisine ilişkin ayrı ayrı modeller geliştirmişler ve elde edilen karlılık sonuçlarını geleneksel sistem karlılık sonucu ile karşılaştırmışlardır.

Kısıtlar teorisi, işletmelerin ana problemini bulma ve bu problemi yok ederek işletmenin gerçek kapasitesini ortaya çıkaran bir yöntemdir. Bunun yanında maliyete bakış açısı ve uygulamaları yönünden piyasa şartlarını irdeleyen gerçekçi bir çözümlemeye sahiptir. Bu anlamda kısıtlar teorisi ile klasik başa baş analizi yöntemi bir araya geldiğinde işletmelerin rekabet ortamındaki durumlarını simüle etmesi ve en karlı ürün karmalarını ortaya koyması beklenmektedir. Çünkü başa baş analizi işletmedeki sabit ve değişken maliyetleri göz önüne alarak işletmenin kara geçiş noktası için ne kadar ürün üretmesi gerektiğini ortaya koymaktadır. Böylece işletmenin piyasada yer edinip edinemeyeceği hakkında fikir verir. Öbür yandan kısıtlar teorisi başa baş analizi ile birlikte kullanıldığı zaman işletmenin kapasite kullanımını artıracak ve klasik başa baş analizinin aksine üretim yerine satışlar üzerinden hareket ederek gerçekçi bir senaryo ortaya koyacaktır. Literatürde yapılan çoğu çalışma benzer sonuçlar ortaya koymuş ve uygun ürün karmaları ile başa baş analizinin tespitleri doğru bir şekilde kullanılmıştır. Bu çalışmada yapılan bu tespitlerin yanında yine kısıtlar teorisi algoritmasından yararlanılarak bir adım öteye geçilmiş ve tespitler kullanılarak işletmedeki darboğaz kısıtların kaldırılması halinde oluşacak senaryolar ortaya konmuştur. Ayrıca yeni oluşacak darboğazlar konusuna da değinilmiştir.

\section{Matematiksel Modelleme}

Matematiksel modellemeye geçilmeden önce kısıtlar teorisinin bazı varsayımları bilinmelidir. Bunlar;

- İşletmenin temel amacı kâr elde etmektir

- Direkt işçilik giderleri, dönem gideri olarak kabul edilmektedir.

- Her mamul için en az bir kısıt vardır

- Zincirde, mamul akışının planlanması zorunludur

Bu varsayımların bilinmesi kısıtlar teorisi ile birlikte kullanılan başa baş analizinin klasik başa baş analizinden farkını ortaya koymaktadır. Klasik başa baş analizi direkt işçilik giderlerini değişken gider olarak kabul etmekteyken kısıtlar teorisi dönem gideri olarak yani sabit gider olarak kabul etmektedir. Bu ayrım oluşturulan matematiksel modellerin farklı olmasına neden olmaktadır. Ayrıca kısıtlar teorisinin algoritması kullanılarak işletmedeki darboğaz kısıtların belirlenip ortadan kaldırılması kolaylaşacaktır.

İşletmede başa baş maliyetini yakalamak için en iyi ürün karmasını bulacak modeller her iki yönteme göre aşağıda oluşturulmuştur. Bu modelin, belli kısıtlar altında işletmeyi en iyi ve en hızlı şekilde kara götüreceği düşünülmektedir.

Model kurulmadan önce kullanılacak kısaltmalar aşağıdaki şekilde tanımlanmıştır.

$\mathrm{X}_{\mathrm{i}}$ : $_{\mathrm{i}}$ etki alanına sahip üretilen ürünün üretim miktarı $(\mathrm{i}=1,2,3,4,5)$

$\mathrm{S}_{\mathrm{i}}$ : i etki alanına sahip ürünlerin satış fiyatı

$\mathrm{T}_{\mathrm{i}}$ : Ürünlerin standart fiili işgücü süresi

$\mathrm{W}_{\mathrm{i}}$ : Ürünler için belirlenen stoklama katsayısı

$\mathrm{C} 1_{\mathrm{j}: \mathrm{j}}$ etki alanına sahip hammadde maliyeti $(\mathrm{j}=1,2,3)$

$\mathrm{C} 2{ }_{\mathrm{i}}$ : Birim Enerji Gideri

$\mathrm{C} 3_{\mathrm{i}}$ : Birim işçilik maliyetleri

$\mathrm{Y} 1_{\mathrm{ij}:}$ Ürünlerin üretiminde kullanılan hammadde miktarları

$\mathrm{Y} 2_{\mathrm{ij}:}$ Ürünlerin makinede işlendiği standart fiili süre

Hammadde(j): j etki alanına sahip teorik makine kapasiteleri

Makine(j): j etki alanına sahip teorik makine kapasiteleri

Stokalanı: Teorik stok alanı kapasitesi

İşü̈cü: Teorik işgücü kapasitesi

D: Sabit maliyet

$\operatorname{Min} z=y$

$\sum_{\mathrm{i}=1}^{5} X i * S i-\sum_{\mathrm{i}=1}^{5} \sum_{J=1}^{3} Y 1 i j * C 1 j * X i-\sum_{\mathrm{i}=1}^{5} C 3 i * X i-\sum_{\mathrm{i}=1}^{5} C 2 i * X i-D=y$

$\sum_{\mathrm{i}=1}^{5} Y 1 i j * X i \leq \operatorname{hammadde}(j)$ 


$$
\begin{aligned}
& \sum_{i=1}^{5} Y 2 i j * X i \leq \text { makine }(j) \\
& \sum_{i=1}^{5} W i * X i \leq \text { stokalanı } \\
& \sum_{i=1}^{5} T i * X i \leq \text { isgücü } \\
& X i \geq 0 \\
& y \geq 0
\end{aligned}
$$

Yapılan modellemede sırasıyla (1) denklem amaç fonksiyonunu ifade etmekte ve modeli sıfıra götürerek başa baş noktasını bulmaya çalışmakta, (2) denklem y değişkenini kısıtlayan satışların değişken ve sabit maliyetlerden farkını, (3) denklem üretilen ürünlerin kullandığı hammadde miktarının toplam hammadde miktarını geçemeyeceğini, (4) denklem üretilen ürünlerin makinedeki toplam fiili işlem sürelerinin makine kapasitesini geçemeyeceğini, (5) denklem üretilen ürünlerin depolanmasında toplam stok alanının geçilemeyeceğini, (6) denklem üretilen ürünlere harcanan toplam işgücü miktarının işgücü kapasitesini geçemeyeceğini, (7) denklem üretilen ürün sayısının sıfırdan büyük veya eşit olacağını ve son olarak denklem (8)'de y değişkenin sıfirdan büyük veya eşit olacağını ifade etmektedir. Kurulan modelden (1) denklem ve (8) denklem çıkarılıp yerine (9) denklem eklendiği zaman klasik başa baş analizine göre işletme karını hesaplayan model elde edilecektir. Model için geriye kalan kısıtlar geçerlidir.

$$
\operatorname{MaxZ}=\sum_{\mathrm{i}=1}^{5} X i * S i-\sum_{\mathrm{i}=1}^{5} \sum_{J=1}^{3} Y 1 i j * C 1 j * X i-\sum_{\mathrm{i}=1}^{5} C 3 i * X i-\sum_{\mathrm{i}=1}^{5} C 2 i * X i-D
$$

Kısıtlar teorisinin özellikleri göz önüne alındığında başa baş analizinin farklı kullanımı sağlanır. Bu kullanımda değişken maliyetler ve sabit maliyetler değişmiş olacak ve kısıtlar teorisinin kullandığı yeni bir kavram olan "kısıtlı katkı payı" devreye girecektir. Kısıtlar teorisine göre işçilik maliyetleri dönem gideri olarak alınmaktadır. Bu yaklaşımda sadece ilk madde malzemeler değişken maliyet olarak yer almaktadır. Buna göre ilk modelde (2) denklem yerine (10) denklem yazıldığgnda kısıtlar teorisine göre başa baş noktasını bulan model elde edilecektir. Diğer kısıtlar bu model için geçerlidir.

$$
\sum_{i=1}^{5} X i * S i-\sum_{i=1}^{5} \sum_{J=1}^{3} Y 1 i j * C 1 j * X i-D=y
$$

Kısıtlar teorisinde karlılık için ise klasik başa baş analizinde olduğu gibi denklem (2) kaldırılıp yerine denklem (11) yazılıp denklem (1) ve denklem (8) modelden çıkarılmıştır. Geriye kalan kısıtlar geçerliliğini korumaktadır.

$$
\operatorname{MaxZ}=\sum_{\mathrm{i}=1}^{5} X i * S i-\sum_{\mathrm{i}=1}^{5} \sum_{J=1}^{3} Y 1 i j * C 1 j * X i-D
$$

\section{Uygulama}

Adana bölgesinde orta ölçekte üretim yapan bir şirket ürettiği beş ürün içinde maksimum kar elde edeceği bir ürün karması elde etmek istemektedir. İşletme üretilen ürünlerin kaynak kullanımı, satış fiyatı ve talep miktarları bilgisine sahiptir. Ancak bu ürün karmasını bulurken kaynak kullanımını en üst seviyede kullanmak ve en hızlı şekilde kara erişmek istemektedir. Bu amaçlar göz önüne alındığında başa baş analizi kara geçme noktasını belirlemek için ideal bir yöntem olarak gözükmektedir. Ancak aynı zamanda kaynakların en iyi şekilde kullanılması amaçlanmakta ve bunun için bir ürün karması belirlenmeye çalışılmaktadır. Bütün bu amaçlar doğrultusunda kısıtlı olan kaynakların doğru kullanımını içeren kısıtlar teorisi ile başa baş analizinin birlikte kullanılması amaca en iyi hizmet edecek yöntem olacaktır. Yapılan çalışmada öncelikle şirkette üretilen ürünlerin üretim koşulları ve daha önce yapılan analizler 1şığında üretim için belirlenen fiili standart süreler göz önüne alınmıştır. Buna göre üretilen beş üründen; birinci ürün için hammadde bir ve üç, ikinci ürün için hammadde iki, üçüncü ürün için hammadde bir ve iki, dördüncü ürün için hammadde iki ve üç, son olarak beşinci ürün için hammadde üç kullanılmaktadır. Makine dağılımına bakıldığında ise birinci makinede (M1) ürün bir ve beş, 
ikinci makinede (M2) ürün bir, iki ve dört, üçüncü makinede (M3) ise ürün üç, dört ve beş üretilmektedir. Ürünler için harcanan işgücü süresi sırasıyla 22, 23, 23, 24 ve 27 dakikadır. Makinelerin ürünler için harcadığ fiili süreler sırasıyla birinci makinede birinci ürün için $6.6 \mathrm{dk}$, beşinci ürün için $8.1 \mathrm{dk}$, ikinci makinede birinci ürün için $6.6 \mathrm{dk}$, ikinci ürün için 6.9, dördüncü üründe $7.2 \mathrm{dk}$, üçüncü makinede ise üçüncü ürün için $13.8 \mathrm{dk}$, dördüncü ürün için $7.2 \mathrm{dk}$, beşinci ürün için $8.1 \mathrm{dk}$ harcanmaktadır.

İşletmede yapılan iş etüdü çalışmaları sonucu her bir ürüne ait olan standart zamanlar hesaplanmış ve her bir ürünün işlendiği makinedeki fiili süre belirlenmiştir. Bu sürelerin işgücü süresi ile ilişkili olduğu görülmüştür. Buna göre U1'in üretildiği makinelerde harcanan zaman işgücü süresinin \%30 kadar, U2'nin üretildiği makinede işgücü süresinin \%30 kadar, U3'ün üretildiği makinelerde işgücü süresinin \%60’u kadar, U4'ün üretildiği makinelerde harcanan işgücü süresinin \%30 kadar ve son olarak U5'in üretildiği makinelerde işgücü süresinin \%30 u kadar bir süre aldığı belirlenmiştir. Üretilen ürünler için kullanılan hammadde miktarları şöyledir: Birinci ürün için 4 gram birinci hammadde (H1) ve 6 gram üçüncü hammadde (H3), ikinci ürün için 4 gram ikinci hammadde (H2) kullanılmakta, üçüncü üründe ise 3 gram (H1), 3 gram (H2), dördüncü üründe 5 gram $(\mathrm{H} 2), 6$ gram $(\mathrm{H} 3)$, son olarak beşinci üründe ise 1 gram $(\mathrm{H} 1)$ ve 4 gram (H3) kullanılmaktadır. İşletmede her çıkan ürün (bitmiş) mamul deposuna alınmakta ve burada standart kolilerle depolanmaktadır. Bu koliler boyutları 30x20x20.ve 40x30x30'dur. Kolilere toplamda sı̆gan ürün miktarı birinci koli (30x20x20) sırasıyla 4, 5, 6’dır. Dördüncü ve beşinci ürün için ikinci koli (40x30x30) kullanılmaktadır ve sırasıyla 10 adet sığabilmektedir. İşletmede bir depolamada en fazla 10 koli üst üste konulmaktadır. Yapılan hesaplamalar sonucu her ürün için hesaplanan stoklama katsayısı belirlenmiş ve bu stoklama katsayısı ürünler için sırasıyla 0.0015, 0.0012, $0.0010,0.0015$ ve 0.0012 'dir. İşletmenin var olan deposu 30 metrekare alana sahiptir.

İşletmede fiili kullanım durumunun dışında aylık teorik kapasiteler hesaplanmıştır. Bu hesaplamalara göre işletme ayda ortalama 20 gün çalışmakta ve bir işgünü 8 saatten oluşmaktadır. İşletmede üretimde çalışan 30 çalışan bulunmaktadır. Bu bilgiler 1şığında işletmenin aylık işgücü kapasitesi $20 * 30 * 480=288.000$ dakikadır.

İşletme ayda belirli partiler halinde hammadde siparişi vermektedir. İşletmenin belirlediği satın alma politikasına göre (H1)'den her biri 10.000 g olmak üzere 2 kere, (H2)'den her biri 14.000 olmak üzere 3 kere, (H3)'den her biri 16.000 olmak üzere 3 kere sipariş verilmektedir. İşletmede kullanılan 3 tip makine mevcuttur. Bu makinelerin sayıları birbirinden farklıdır. Toplam makine kapasiteleri işgücü kapasitesine benzer bir şekilde hesaplanmıştır. İşletmenin ayda çalıştığı ortalama gün sayısı ile makine sayısı ve günde çalışılan süre çarpılarak her bir makineye ait teorik kapasiteler hesaplanmıştır. Buna göre M1 67.200 dk, M2 ve M3 ise 144.000 dakikalık kapasiteye sahiptir. İşletmede yapılan bu tespitlerden amaca yönelik başa baş ve karlılık modellerini kurmak için gerekli maliyetler hesaplanmıştır. Buna göre satış fiyatları sırasıyla 19, 20,16,18, 23, birim enerji giderleri 1.3, 1.5, 2.5, 0.8, 1.2, birim işçilik giderleri ise 2.3, 2.2, 2.4, 2.5 ve 2.7 'dir. Bunun haricinde hammadde birim maliyetleri sırasıyla 0.6, 1.1, 0.8, işletme sabit dönem giderleri ise 155.000 liradır.

Kurulan modelin iki türlü kullanımı söz konusudur. Birinci kullanım klasik başa baş analizi yöntemidir. Klasik başa baş yöntemi işletme maliyetlerine üretim mantığıyla bakmaktadır. Bu mantığa göre üretimin fazla olması sabit maliyetleri düşüreceğinden ürünler daha az maliyetle üretilmiş olacaktır. Üretilen ürünler kara geçişte ne derece katkı sağlıyorsa bu ürünler o derecede önem kazanmaktadır. Kurulan modelde bu yönteme ek olarak kapasiteler nedeniyle oluşan kısıtlar da dikkate alınarak kapasitelerin en iyi şekilde kullanılması sağlanacak ve böylece sadece katkı payı yüksek olan ürünler değil aynı zamanda kısıtlara göre en yüksek karı elde edecek seçim de yapılmış olacaktır. Buna göre işletmenin U2 ve U5'i üretmesi kısıtlar dâhilinde başa baş noktasını yakalamada en avantajlı ürünler olacaktır. Program sonucunda U2'den 5679.144 ve U5'den 5828.877 adet üretildiğinde işletme kara geçme noktasına gelmiş olacaktır. Bundan sonraki üretilen her ürün işletmeye katkı payına bağlı olarak kar getirecektir.

Tablo 1. Üretilen ürünlerin katkı payı TL/br 
Antmen, Z., F., Erik, A. / Journal of Yasar University, 2019, 14/55, 266-276

\begin{tabular}{|c|c|c|l|c|}
\hline Ürünler & $\begin{array}{l}\text { Birim hammadde } \\
\text { gideri(TL/br) }\end{array}$ & $\begin{array}{l}\text { Birim İşçilik } \\
\text { Gideri(TL/br) }\end{array}$ & $\begin{array}{l}\text { Birim } \\
\text { Enerji } \\
\text { Gideri(TL/br) }\end{array}$ & $\begin{array}{l}\text { Katkı } \\
\text { Payı } \\
\text { (TL/br) }\end{array}$ \\
\hline U1 & 7.8 & 2.2 & 1.3 & $\mathbf{1 1 . 3}$ \\
\hline U2 & 4.4 & 2.1 & 1.5 & $\mathbf{8}$ \\
\hline U3 & 5.1 & 2.5 & 2.5 & $\mathbf{1 0 . 1}$ \\
\hline U4 & 10.9 & 2.4 & 0.8 & $\mathbf{1 4 . 1}$ \\
\hline U5 & 4.2 & 2.7 & 1.2 & $\mathbf{8 . 1}$ \\
\hline
\end{tabular}

Model sonuçları dikkate alındığında başa baş noktasını yakalamak için işletme kapasitesinin kullanımları işletmenin üretkenliğini ve darboğaz kaynaklarını ortaya koymaktadır. Buna göre hammadde, makine, işgücü ve stok alanı kullanımları arasından işgücü kapasitesinin tamamı kullanılmıştır. Kullanılan kapasite aynı zamanda işletmenin kalan üretim potansiyelini ortaya koyacaktır. Kurulan model Gams.side programında çözülmüş ve sonuçları üzerinde yapılan analizler sonucu başa baş noktasını daha hızlı yakalamak için işletmenin U2 ve U5 ürünlerini üretmesinin daha anlamlı olduğu görülmüştür. Model aynı zamanda işletmenin kapasitesini dikkate alarak çalıştığı için kapasitelerin de verimli olarak kullanılmasını ve buna göre üretim kararı vermeyi sağlamaktadır. Kurulan model maksimum karı sağlamak için hangi ürün karmasını üretmenin de cevabını vermektedir. Daha önce başa baş noktası için kurulan amaç fonksiyonunu değiştirmek bu modeli kurmak için yeterli olacaktır. Yapılan amaç fonksiyonu değişikliğinden sonra işletmenin kapasitesi de dikkate alınarak yapabilecek maksimum kar 2006.119163 TL olarak bulunmuştur.

Amaç fonksiyonu değiştiği için artık klasik başa baş noktası yönteminden doğan katkı paylarına göre üretimin yanında işletmenin kapasitesine göre farklı ürünlerden farklı miktarlarda üretme opsiyonu kullanılarak kar daha yüksek bir noktaya çıkarılabilir mi? sorusu doğmuştur. Çalışmada en yüksek karı elde etmek için hangi ürünün üretilmesi gerektiğine karar verilmiştir. Bu da başa baş noktası bulunurken seçilen U2 ürünün karlılığını maksimuma çıkarmakla aynı derecede önem arz etmediğini göstermiştir. Bu seçime göre kapasitelerin kullanım oranları arasında işgücü ve makine 1 tam kapasiteli kullanılarak darboğazı oluşturan iki kısıt olmaktadır.

Tablo 2. Kısıtlar Teorisine Göre Hesaplanan Kısıtlı Katkı Payları

\begin{tabular}{|c|c|c|c|c|}
\hline Ürünler & $\begin{array}{c}\text { Satış } \\
\text { Fiyatları }\end{array}$ & $\begin{array}{c}\text { Birim } \\
\text { Hammadde } \\
\text { Gideri }\end{array}$ & $\begin{array}{c}\text { Birim } \\
\text { Enerji } \\
\text { Gideri }\end{array}$ & $\begin{array}{c}\text { Kısıtlı } \\
\text { Katkı } \\
\text { Payı }\end{array}$ \\
\hline U1 & 19 & 7,8 & 1,3 & $\mathbf{9 , 9}$ \\
\hline U2 & 20 & 4,4 & 1,5 & $\mathbf{1 4 , 1}$ \\
\hline U3 & 16 & 5,1 & 2,5 & $\mathbf{8 , 4}$ \\
\hline U4 & 18 & 10,9 & 0,8 & $\mathbf{6 , 3}$ \\
\hline U5 & 23 & 4,2 & 1,2 & $\mathbf{1 7 , 6}$ \\
\hline
\end{tabular}

Klasik başa baş analizinden farklı olarak denklemde birim işçilik giderleri ve birim enerji giderleri amaç fonksiyonda yer almamaktadır. Bunun yerine bu maliyetler dönem gideri olarak sayılmakta ve sabit maliyete eklenerek sabit maliyetin değeri 198.000 liraya çıkarmaktadır. Bu değişiklik başa baş noktasına, yapılan satışlar açısından bakma gibi ayrı bir bakış açısı getirmiştir. Aşağıdaki tabloda her ürün için kısıtlar teorisinde kullanılan kısıtlı katkı payları hesaplanmıştır.

Kısıtlar teorisinin varsayımları altında oluşturulan modelde, amaç fonksiyonu değiştiğinden dolayı başa baş noktasını yakalamak için U5 ürününden 5464.286 ve U2 ürününden ise 6107.143 adet üretilmesi gerekmektedir. Klasik başa baş noktası yaklaşımı ile üretilen ürün miktarının aksine kısıtlar teorisinde başa baş analizini yakalamak için toplamda daha fazla ürün üretilmesi gerektiği ortaya çıkmaktadır. Bunun haricinde yine kısıtlar teorisinin varsayımları altında üretme yönelimi değişmektedir. Buna göre farklı olarak U2 den daha fazla ürün üreterek U5 ürününden daha az üretilmiş ve başa baş noktası yakalanmıştır.

Kısıtlar teorisinde üretilen ürünlerin klasik başa baş analizinde üretilen ürünler ile aynı olduğu ve aynı miktarda üretildiği görülmüştür. Bu da kapasiteleri de aynı oranda kullandığını göstermektedir. Ancak amaç fonksiyonu değerine bakıldığında farklılık olduğu görülmüştür. Bu da kısıtlar teorisinin, işçilik ve enerji giderlerini dönem gideri olarak kabul etmesi sonucu, sabit maliyetlerin yükselmesinden kaynaklanmaktadır. Kısıtlar teorisine göre işletme 1.379,066 TL kardadir. 


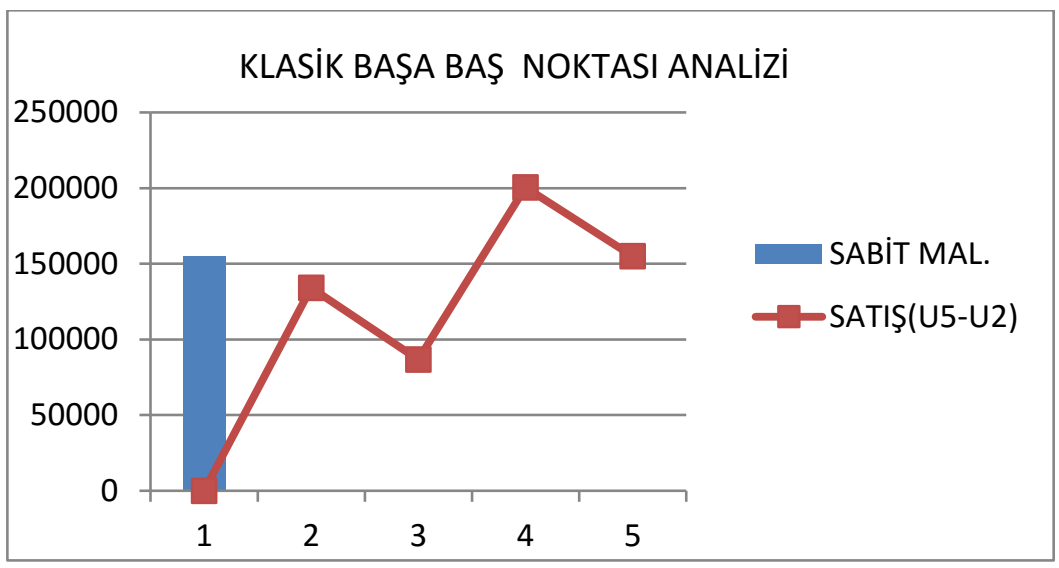

Şekil 2. Klasik Başa baş Noktası Analizi Davranış Grafiği

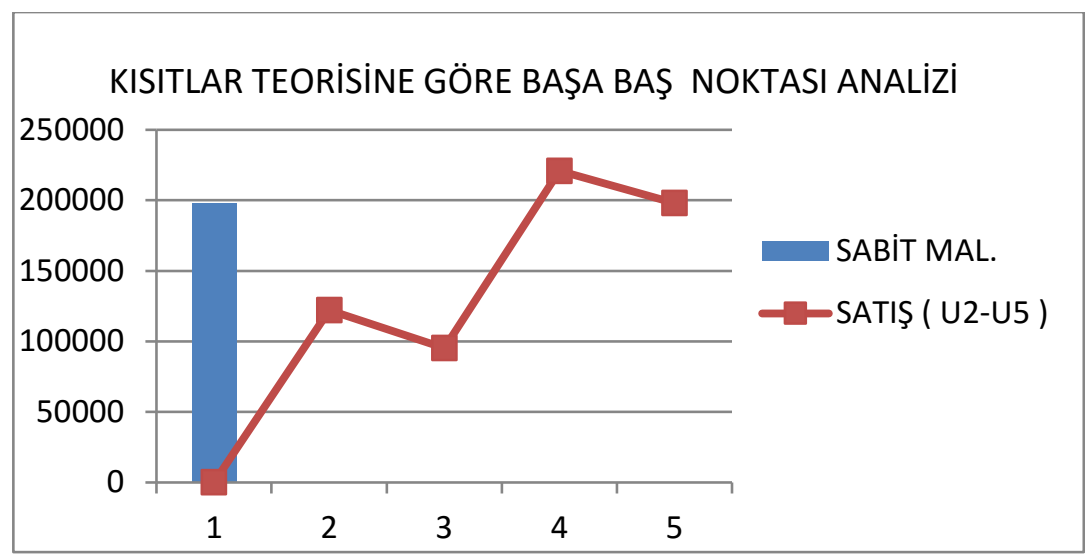

Şekil 3. Kısıtlar Teorisine Göre Başa baş Noktası Analizi Davranış Grafiği

Yukarıdaki grafiklerde de görüleceği gibi iki yöntem arasında bir üretim yönelim farkı bulunmaktadır. Bu yönelim farkı, kar için yapılan analizde ortadan kalkmaktadır. Bu durum aynı zamanda modelin de kapasiteleri dikkate almasından kaynaklanmaktadır. Kısıtlar teorisi bu aşamaya kadar analiz aracı olarak kullanılmıştır. Bu aşamadan sonra kısıtlar teorisinin geliştirici algoritması olan kısıtlar teorisinin beş adımı (şekil 1) kullanılarak işletmenin kar edebilmesinin önündeki en önemli kısıt veya kısıtlar bulunarak kaldırılmaya çalışılmıştır.

İşletmede işgücü kapasitesi ve makine 1'in kapasitesi tamamen kullanılmıştır. Kapasitelerden makine 1'in kapasitesi artırılsa bile üretimde bir değişiklik olmayacaktır. Üretilen ürünlerde işgücü kapasitesi kritik kısıt olmaktadır. Yapılacak ilk düzenleme işgücü kapasitenin artırılması olarak görülmektedir. İşgücü kapasitenin artırımı için işletmeye 5 çalışan alınmıştır. Burada işe alınacak çalışan sayısına karar verilirken modeldeki çalışan sayısı kademeli olarak artırılarak denemeler yapılmıştır. Çalışan sayısını darboğazdan çıkaran sayı 5 olarak bulunmuştur. İşletmeye 5 çalışanın maliyeti aylık 7.500 lira olmuştur.

Yapılan değişiklik işletmenin karını 1.379 dan 26.435'a kadar çıkarmaktadır. Üretimi artan ürün ise U2 olmuştur. Ancak kısıtlı katkı payına ve kısıt oluşturan kapasite dikkate alındığında üretimi artırılması gereken asıl ürünün U5 olması gerekmektedir. Bunun için işgücünün yanında makine 1'in kapasitesinin de artırılması gerekmektedir. İşletmede kısıtları ortadan kaldırmak ve karlılığı artırmak için maliyetleri işletmeye 7.500 lira olan 5 işçiyi işe almak diğer bir aksiyon ise toplam maliyetleri 15.000 lira üç tane makine 1 türünden makine almak olacaktır. Genel olarak işletmeye dönemde 22.500 lira sabit maliyet eklenmiş olacaktır. Yalnız bu maliyetin 15.000 lirası olan makine maliyeti bu dönemde artacak kardan karşılanabilirse diğer dönemlerde kalıcı olarak 7.500 lira sabit maliyet işletmeye yansımış olacaktır. Yapılan değişiklikler sonucu üretilen miktar ve elde edilen kar 13.166.98 TL olmuştur.

Kullanılan iki yöntemin temelde farklı olması kısıtlar teorisinin, bir işletmenin kar edebilmesi için satış yapması ve bu karı artırmak için ürünlerin satışını kısıtlayan durumları ortadan kaldırması isteğinden kaynaklanmaktadır. Tablo 3'de kısıtlar teorisinin ve klasik başa baş analizinin sonuçları bir arada yer almaktadır. Bu durumdaki farklılıklar işletmenin durumu hakkında bilinenlerin üzerine iki farklı bakış açısıdır. 
Tablo 3. Klasik Başa baş Analizi

\begin{tabular}{|c|c|c|c|c|c|}
\hline \multicolumn{7}{|c|}{ KLASIK BAŞA BAŞ ANALIZI } \\
\hline SATIŞ TUTARI \\
\hline ÜRÜNLER & U1 & U2 & U3 & U4 & U5 \\
\hline ÜRETİLEN MIKTAR & 0 & 5679.1 & 144 & 0 & 5829 \\
\hline SATIŞ HASILATI & 0 & 113583 & 0 & 0 & 134064 \\
\hline TOPLAM SATIŞ HAS. & \multicolumn{5}{|c|}{247647.051} \\
\hline DEĞISŞKEN MALIYETLER \\
\hline ÜRÜNLER & U1 & U2 & U3 & U4 & U5 \\
\hline HAMMADDE MAL. & 0 & 24988 & 0 & 0 & 24481 \\
\hline İŞÇİİK MAL. & 0 & 11926 & 0 & 0 & 15738 \\
\hline ENERJİ MALIYYTİ & 0 & 8518.7 & 0 & 0 & 6994.7 \\
\hline TOPLAM MAL. & \multicolumn{5}{|c|}{92647.0557} \\
\hline SABIT MALIYETLER \\
\hline DÖN. SAB. MAL. & \multicolumn{7}{|c|}{155000} \\
\hline BAŞA BAŞ DEĞERİ &
\end{tabular}

Tablo 4. Kısıtlar Teorisine Göre Başa baş Analizi

\begin{tabular}{|c|c|c|c|c|c|}
\hline \multicolumn{7}{|c|}{ KISITLAR TEORISINE GÖRE BAŞA BAŞ ANALIZİ } \\
\hline \multicolumn{6}{|c|}{ SATIŞ TUTARI } \\
\hline ÜRÜNLER & U1 & U2 & U3 & U4 & U5 \\
\hline ÜRETİLEN MIKTAR & 0 & 6107.1 & 0 & 0 & 5464.3 \\
\hline SATIŞ HASILATI & 0 & 122143 & 0 & 0 & 125679 \\
\hline TOPLAM SATIŞ HAS. & \multicolumn{5}{|c|}{247821.438} \\
\hline DEĞIŞKEN MALIYETLER \\
\hline ÜRÜNLER & U1 & U2 & U3 & U4 & U5 \\
\hline HAMMADDE MAL. & 0 & 26871 & 0 & 0 & 22950 \\
\hline İŞÇİLIK MAL. & 0 & 0 & 0 & 0 & 0 \\
\hline ENERJİ MALIYETİ & 0 & 0 & 0 & 0 & 0 \\
\hline TOPLAM MAL. & \multicolumn{5}{c|}{49821.4304} \\
\hline SABİT MALIYETLER \\
\hline DÖN. SAB. MAL. & \multicolumn{5}{c|}{0.0076} \\
\hline BAŞA BAŞ DEĞERİ
\end{tabular}

Yapılan analizler sonucu kısıtlar teorisi, işletmenin görünenden daha az kar elde ettiğini ortaya koymaktadır. Klasik başa baş analizinde, üretim miktarının kar noktasına daha az ürün üreterek gelindiğini ve böylelikle bundan sonraki satışların karının daha fazla gösterildiği anlaşılmaktadır. Kısıtlar teorisinde ise ürünlerin satılsa da satılmasa da işçilik ve enerji giderlerinin aynı olacağını ve bunun da dönem gideri olarak görülmesi gerektiğini belirtmektedir. Böylece kar etmek için ne kadar satış yapılması gerektiği ortaya konmuş olacaktır.

Klasik başa baş analizi sonuçları incelendiğinde model U1 ve U4 ürünlerini üretme yöneliminde bulunmazken U2, U3 ve U5 ürünlerini üretme kararı almıştır. Bu üretim kararı incelendiğinde kara geçiş noktasını 247647 TL'lik satış tutarında yakalamıştır. Buna karşın kısıtlar teorisi ürün karmasını sadece U2 ve U5'den oluşturarak kara geçiş noktasını 247821 TL'lik bir satış tutarında yakalamıştır. Bu sonuçlar ilk bakıldığı zaman bir anlam ifade etmeyebilir ancak ürün yönelimi darboğaz kısıtları etkilemektedir. Bu durum daha fazla kar ettiren ürün için gerekli kaynağın başka bir ürünün 
üretiminde kullanılmasına neden olabilmektedir. Kısıtlar teorisi bu noktada doğru kaynak kullanımını sağlayarak işletmenin daha fazla kar etmesini sağlamaktadır.

Yapılan incelemede işletmenin ilk dönemdeki karı 13.166 lira olmasına karşı bu sonraki dönemlerde makinelerin amortisinden sonra 28.166 ya çıkacaktır. Ancak bu iyileştirmeler yapılırken işletmenin karlılığı açısından bir başka opsiyon görülmüştür. Sadece işgücünün seviyesi 5 çalışan alımı ile artırıldığında elde edilen kar 26.435 lira olarak şu anda makine alımına rağmen çok fazla artmayan kara yakın bir kar oluşmuştur. İşletmenin sadece işgücü kapasitesini artırmak için çalışan alması işletme açısından hem daha az bir maliyete neden olacaktır hem de çok daha yüksek bir kar elde edilecektir. Bu sebeple makine 1 için harcanacak olan 15.000 liraya işletmenin var olan çalışanı 30'dan 40 çıkarılarak sabit maliyeti 198.000 liradan 213.000'e çıkarılmıştır. Böylece kısıtlar teorisinin 5 adımı uygulanmadan önce 1.379 olan kar muazzam bir artış göstererek 51.492'ye çıkmış olacaktır.

\section{Sonuç ve Öneriler}

Kısıtlar Teorisi, üretim sürecindeki ilk madde ve malzeme, yarı mamul ve mamul stoklarını en aza indirerek maliyetleri düşürmekte ve kârlılığı arttırmaktadır. Kısıtlar Teorisinin düşük maliyetli, kolay anlaşılır nitelikte olması uygulamadaki başarısını arttırmaktadır. Çalışmada görüldüğü üzere anlaşılması kolay ve uygulaması da basit bir yöntem olmakla beraber işletmeye olan katkısı yüksek düzeydedir.

Başa baş analizine kısıtlar teorisinin katkısı başa baş analizini bir belirleyici analizin ötesinde geliştirici analize götürmüş ve piyasa şartlarını daha gerçekçi şekilde alarak satışlar üzerinden yaptığı hesaplamalarla işletmeye daha fazla katkıda bulunmasını sağlamıştır. Bu yönüyle başa baş analizi kısıtlar teorisi ile işletme üzerinde oldukça olumlu katkıda bulunduğu söylenebilir.

Kisitlar Teorisinin gerek kısıtların ortadan kaldırılmasına odaklanması gerekse de direkt ilk madde ve malzeme giderleri dışındaki tüm giderleri sabit kabul etmesi, kısa vadede etkili olması yorumunda bulunulmasına neden olmaktadır. Bu eleştiriye karşılık, Robert Kee Kısıtlar Teorisinin ve dolayısıyla geleneksel maliyet muhasebesinin aksine maliyet yerine işletme karlılığına odaklanmış olan kısıtlar teorisinin muhasebe kısmı Süreç Katkı (Dönüşüm) Muhasebesinin işletmelerde Faaliyet Tabanlı Muhasebe ile birlikte entegre bir şekilde uygulanması durumunda, Kısıtlar Teorisinin kısa vadeli çözümlemelerinin uzun vadeli çözümlemeler haline geleceğini ve bu şekilde söz konusu olumsuzluğun aşılabileceğini belirtmektedir.

İşletme yapılan çalışmayı devam ettirerek oluşan işgücü kısıtını tamamen ortadan kaldırıp ve yukarıda belirtildiği üzere bu konudaki çalışmayı bu alanda bir diğer popüler yaklaşım olan ve maliyetleri faaliyet bazlı inceleyen faaliyet tabanlı muhasebe ile birleştirirse daha kalıcı bir sonuç alınmış olacaktır. Bunun dışında yapılan iyileştirmelerin bir kısmı da işletmenin kendi içinde yatmaktadır. Özellikle daha fazla kar edilmesi için var olan makine kapasitelerini verimli kullanacak yeni ürünler çıkarabilir veya bunu kiralama yoluna gidebilir. Bu anlamda çalışmada ele alınan konunun başka bir yönü de ortaya çıkmaktadır. Kısıtlar teorisinin maliyet uygulamalarında kullanımı ile yapılacak detaylı çalışmalar önemli darboğazları tespit etmede ve bunu çözmede kullanılabilecek anlaşılır bir yöntem olarak daha etkin kullanılabilir. $\mathrm{Bu}$ anlamda sadece tespit değil aynı zamanda kararların alınmasında kısıtlar teorisinin beş adımı daha aktif kullanılabilir.

KAYNAKÇA 
Akman, Gülşen, Karakoç, Çağın, "Yazılım Geliştirme Prosesinde Kısıtlar Teorisinin Düşünce Süreçlerinin Kullanılması”, İstanbul Ticaret Üniversitesi Fen Bilimleri Dergisi, 4 (7), 103-121, 2005.

Atay, Güven, “Kısıtlar Teorisi Ve Sap Projesinde Kısıtlar Teorisi Düşünce Süreçlerinin Uygulanması”, Yüksek Lisans Tezi, Marmara Üniversitesi, İstanbul, 2009.

Atmaca, Metin, Terzi, Serkan, "Stratejik Maliyet Yönetimi Açısından Tam Zamanında Üretim Felsefesi İle Kısıtlar Teorisinin Karşılaştırmalı Olarak İncelenmesi”, Marmara Üniversitesi İ.İ.B.F. Dergisi, 12 (1), 293-309, 2007.

Ayanoğlu, Murat, Şakar, Merve, "Bir Kargo Firmasının Ek Taleplerinin Karşılanması İçin Kısıtlar Kuramı Yaklaşımı Uygulanması”, İşletme Bilimi Dergisi, 3(2), 19-38, 2015.

Aytekin, Fatma Gözde, Yörükoğlu, Hülya, Akman, Gülşen, “Kısıtlar Teorisi Yaklaşımı İle Kurumsal Bilgi Teknolojileri Yönetimi Talep Sistemlerinin Iyileştirilmesi”, Organizasyon Ve Yönetim Bilimleri Dergisi, 4 (2), 39-49, 2012.

Basık, Feryal Orhon, Rekabet Stratejisinde Maliyet Yönetimi, S. 411-412, Türkmen Kitapevi, İstanbul, 2012.

Boyd, Lynn, Gupta, Mahehs, Constraints Management: What Is The Theory? International Journal Of Operations \& Production Management, Vol. 24 Issue: 4, 350-371, https://Doi.Org/10.1108/01443570410524631 , 2009.

Büyükyılmaz, Ozan, Gürkan, Serhan, Süreçlerde En Zayıf Halkanın Bulunması: Kısıtlar Teorisi, Zkü Sosyal Bilimler Dergisi, 5 (9), 117-195, 2009.

Çolak, Faruk, Kısıtlar Teorisi Düşünme Süreçleri Yaklaşımı İle Ağaç Endüstrisinde Lojistik Süreçlerinin İileştirilmesi, Yüksek Lisans Tezi, Kocaeli Üniversitesi, Kocaeli, 2013.

Demircioğlu, Elif N., Demircioğlu, Mert, Üretme-Satın Alma Kararlarında Faaliyete Dayalı Maliyet Sistemi Ve Kısıtlar Teorisi: Doğrusal Programlama İle Örnek Uygulama, Mustafa Kemal Üniversitesi Sosyal Bilimler Enstitüsü Dergisi, 13 (33), 316-333, 2016.

Gaga, Onur, Süreç Analizi Ve Süreç Iyileştirme Metodolojisi Ve Kısıtlar Teorisi Yöntemiyle Süreç Analizi Uygulanması, Yüksek Lisans Tezi, Yıldız Teknik Üniversitesi, İstanbul, 2009.

Gerı, Nitza, Nıv, Ahituv, A Theory Of Constraint Approach To Interorganizational Systems Implementation, Information Systems And E-Business Management, 6 (4), 341-360, 2008.

Goldratt, Eliyahu M., What İs This Thing Called Theory Of Constraints And How Should It Be Implemented?, S. 4-8, The Northern River Pres, Great Barrington, 1990.

Golmohammadi Davood, A Study Of Scheduling Under The Theory Of Constraints, Int J. Production Economics 165 S. 38-50, United States, 2015.

Izmailov, Azar, Korneva, Diana, Kozhemiakin, Artem, Effective Project Management With Theory Of Constraints, 5th International Conference On Leadership, Technology, Innovation And Business Management, Pp. 96-103, 2016.

İlhan, Eda, Klsitlar Teorisi Ve Bir Üretim İşletmesinde Uygulama, Yüksek Lisans Tezi, Uludağ Üniversitesi, Bursa, 2014.

Kaygusuz, Sait Y., Üretim veya Satın Alma Kararlarında Klsitlar Teorisi ve Ms Excel Office Programlarının Birlikte Kullanılması, İktisadi ve İdari Bilimler Dergisi, 20 (2), 159-177, 2006.

Kaygusuz, Sait Y., Kısıtlar Teorisi ve Maliyet Hacim Kar Analizi: Bir Çalışma Sayfası Modellemesi, Muhasebe ve Finansman Dergisi, 171-188 2011.

Küçüksavaş, Nihat,Tanış, Veyis Naci, Ünal, Elif N., Kısıtlar Teorisi Ve Bir Üretim Iş̧letmesinde Uygulama, Ç.Ü. Sosyal Bilimler Enstitüsü Dergisi, 14 (2), 433-448 2005.

Küçüksavaş, Nihat, Demircioğlu, Mert, Ünal, Elif N., Optimal Ürün Karması Belirlemede Faaliyete Dayalı Maliyet Sistemi ve Kısıtlar Teorisi, Ç.Ü. Sosyal Bilimler Enstitüsü Dergisi, 15 (2), 327-344 2006.

Küçüksavaş, Nihat, Demircioğlu, Mert, Demircioğlu, Elif N., Klsitlar Teorisinin Diğer Muhasebe ve Yönetim Teknikleriyle İlskisi, Çukurova Üniversitesi İibf Dergisi, 14 (1), 42-55, 2010.

Özdemir, Selçuk, Kısitlar Teorisine Dayalı Bir Yönetim Muhasebesi Yöntemi: Katkı Muhasebesi Ve Bir Uygulama, Yüksek Lisans Tezi, Uludağ Üniversitesi, Bursa 2007.

Şahbaz, İhasani, Kısıtlar Teorisi ve Bir İmalat Işsletmesinde Uygulama, Yüksek Lisans Tezi, Celal Bayar Üniversitesi, Manisa, 2005.

Utku Demirel, Burcu, Ersoy, Ayten, Kısıtlar Teorisi Ve Süreç Katkı Muhasebesinin Geleneksel Ve Çăgdaş Yönetim/Maliyet Muhasebesi Yöntemleri İle Karşılaştırılması, Journal Of Yaşar University, 3 (11), 1627-1661. 2008

Yüksel, Hilmi, Klsıtlar Teorisinin Düşünce Süreçleri Kullanılarak Bir Üretim İşletmesinin Etkinliğinin Artırılması, Journal Of Yaşar University, 21(6), 3622-3633, 2011. 